\title{
Anti-dyslipidemic properties of green gold nanoparticle: improvement in oxidative antioxidative balance and associated atherogenicity and insulin resistance
}

\author{
Reyhane Javanshir ${ }^{1}$, Moones Honarmand ${ }^{2}$, Mehran Hosseini ${ }^{3}$ and Mina Hemmati ${ }^{4,5^{*}}$ (D)
}

\begin{abstract}
Background: Nowadays, the green synthesis of AuNPs in the presence of plants has been attracted a lot of attention. Herein, in vivo antidiabetic activity of AuNPs synthesized using Ziziphus jujuba in streptozotocin-induced diabetic rats has been evaluated.

Methods: Formation of AuNPs was confirmed by UV-vis, HR-TEM and XRD. Different doses of jujube gold nanoparticles $(0.5$ and $1 \mathrm{mg} / \mathrm{kg}$ ) were used to treat streptozotocin-induced diabetic rats in different groups. At the end of experiment (21 days), serum level of fasting blood glucose (FBG), insulin, Body weight, HOMA-IR, vitamin D, ALT, AST, urea, creatinine, lipid profile, prooxidant-antioxidant balance (PAB) and liver oxidative stress markers were determined.

Results: results showed a significant decrease in the level of liver MDA $(P=0.001)$, fasting blood glucose $(P=$ 0.0001), HOMA-IR $(P=0.0001)$, ALT $(P=0.0001)$, AST $(P=0.0001)$, urea $(P=0.02)$, Triglycerides $(P=0.002)$, Total cholesterol $(P=0.0001), \mathrm{PAB}(P=0.0001)$ and AIP $(P=0.001)$ and in contrast a significant increase total antioxidant capacity $(P=0.02)$, insulin $(P=0.03)$, Body weight $(P=0.0001)$ and vitamin $D(P=0.0001)$ in the AuNPs-treated diabetic group compared to the diabetic rats. No significant change was observed in the total thiol group ( $P=$ 0.18), LDL-C $(P=0.43)$, creatinine $(P=0.09)$ and HDL-C $(P=0.71)$ level in diabetic rats treated with AuNPs compared to diabetic rats.
\end{abstract}

Conclusion: The results of this study proves that green AuNPs exerted promising antidiabetic and anti-oxidant properties.

Keywords: Diabetes mellitus, Ziziphus jujube, AuNPs, Prooxidant antioxidant balance, Oxidant/antioxidant status

\section{Introduction}

Diabetes mellitus (DM) is a growing problem around the world that requires financial and health care policies [14]. Many studies show the role of metals in development of drugs and glucose metabolism [5, 6]. These metals, as

\footnotetext{
* Correspondence: mina1hemmati@yahoo.com; mhemmati@zums.ac.ir ${ }^{4}$ Biochemistry Department, Faculty of Medicine, Zanjan University of Medical sciences, Zanjan 4513956111, Iran

${ }^{5}$ Biochemistry Department, Faculty of Medicine, Birjand University of Medical Sciences, Birjand 9717853577, Iran

Full list of author information is available at the end of the article
}

nanoscale, play a significant role in reducing blood glucose and managing diabetes [7]. Many researchers reported the role of metals such as Vanadium, chromium, magnesium, copper, zinc and gold in blood sugar maintenance and diabetes therapy [8]. Gold nanoparticles have been considered as the most used nanomaterial in medical science due to their unique structural, optoelectronic, biochemical and sensing properties [9]. The AuNPs have been applied in various medical fields such as drug delivery, medical imaging and tumor therapy [10-12].

\section{Springer Open}

(- The Author(s). 2020 Open Access This article is licensed under a Creative Commons Attribution 4.0 International License, which permits use, sharing, adaptation, distribution and reproduction in any medium or format, as long as you give appropriate credit to the original author(s) and the source, provide a link to the Creative Commons licence, and indicate if changes were made. The images or other third party material in this article are included in the article's Creative Commons licence, unless indicated otherwise in a credit line to the material. If material is not included in the article's Creative Commons licence and your intended use is not permitted by statutory regulation or exceeds the permitted use, you will need to obtain permission directly from the copyright holder. To view a copy of this licence, visit http://creativecommons.org/licenses/by/4.0/. 
In recent years, the different chemical and physical methods (e.g.: hydrothermal, sol-gel process, chemical vapor deposition, chemical precipitation and microwave) were reported for the synthesis of AuNPs [13, 14]. Nowadays, the green synthesis of AuNPs in the presence of plants has received much attention [15-18]. One of plants that has fabulous medicine properties is Ziziphus jujuba (jujube). The fruit of jujube tree is used as antioxidant, anthelmintic, hepatoprotective, antiinflammatory, antibacterial, and also anti-inflammation agent [19-22]. There are few reports for biosynthesis of nanoparticles using jujube fruit extract [23-27]. In this study, we introduced an easy and safe route for the biosynthesis of green AuNPs and therapeutic potential of the AuNPs in diabetes.

\section{Materials and methods}

Chemical compounds

Chloroauric acid (HAuCl4.3H2O) was obtained from LobaChemie. Streptozotocin and TMB powder (Sigma, Aldrich). Peroxidase enzyme (Darmstadt, Germany). Chloramine $\mathrm{T}$ trihydrate (Applichem: 402862, Darmstadt, Germany), hydrogen peroxide (30\%) (Merck). The UV-Vis spectra were recorded by a 2501 UV/VIS Spectrophotometer (Shimadzu, Kyoto, Japan). The X-ray diffraction (XRD) patterns were obtained through a Bruker D8-advance X-ray diffractometer with $\mathrm{Cu} \mathrm{Ka}(\mathrm{k}=0.154$ $\mathrm{nm})$ radiation.

\section{Preparation of dried jujube fruits aqueous extract}

The jujube fruits were collected from gardens located in South Khorasan in Iran. The fruits were washed with double distilled water and dried in the shade. The dried fruits were completely powdered. Then, $20 \mathrm{~g}$ of dried powdered fruit of jujube was dispersed in $200 \mathrm{ml}$ of double distilled water and refluxed at $80 \mathrm{C}$ for $30 \mathrm{~min}$. The obtained extract was centrifuged at $5000 \mathrm{rpm}$, and filtered using Whatman No. 1 filter paper. The filtrate was applied for the green synthesis of gold nanoparticles.

\section{The green synthesis of AuNPs using jujube}

Four milliliter of the jujube aqueous extract was added drop wise to $25 \mathrm{~mL}$ of $1 \mathrm{mM}$ aqueous solution of $\mathrm{HAuCl} 4.3 \mathrm{H} 2 \mathrm{O}$ with vigorous stirring at room temperature for $20 \mathrm{~min}$. The stirring of solution was continued for $2 \mathrm{~h}$. After $10 \mathrm{~min}$ of addition of extract, the color of the solution was changed from pale yellow to dark purple. The color change was corroborated the formation of AuNPs. Also, reduction of $\mathrm{Au}+$ ions and their conversion to $\mathrm{Au}$ nanoparticles were monitored by UV-Vis spectroscopy. The intermittent sampling of aliquots $(0.1 \mathrm{ml})$ of aqueous component that diluted to 20 times with double distilled water was used and their UV-Vis spectra recorded.

\section{Experimental design}

In this study, 20 male Sprague-Dawley rats weighing 180-200 g were randomly divided into 4groups of 5each and treated for 21 days. Group I: Healthy control, Group II: Diabetic, Group III: Diabetic, with AuNPs (0.5 mg/kg) and Group IV: Diabetic with AuNPs (1 mg/kg). Diabetes was induced by single intraperitoneal (IP) injection of streptozotocin (STZ) (45 mg/kg body weight) (dissolved in sodium citrate buffer). Seventy-two hours after injection of STZ, animals with serum glucose levels more than $16.6 \mathrm{mM}$ were considered to be diabetic. At the end of study, animals were anesthetized by sodium thiopental $(35 \mathrm{mg} / \mathrm{kg})$. Blood was collected via cardiac puncture in sterile vials. For preparing serum, all tubes were centrifuged at $3000 \mathrm{rpm}$ for $15 \mathrm{~min}$.

\section{Biochemical measurements}

Serum concentrations of FBG, BUN, and creatinine, and AST, ALT and lipid profile were measured by desired photometric methods (Pars Azmun, Iran). The level of insulin was measured using ELISA kits adapted to Epoch microplate reader (BioTek, USA). The atherogenic index of plasma (AIP), calculated as log [TG]/[HDL-C] is used as a significant predictor of atherosclerosis [28]. For assessment of insulin resistance (HOMA-IR) $=[$ fasting serum insulin $(\mathrm{mU} / \mathrm{mL}) \mathrm{x}$ fasting serum glucose (mmol/ L)/22.5)] index was used.

\section{Evaluation of oxidative stress status in diabetic liver tissue under treatment with jujube gold nanoparticles} At the end of the treatment period, the liver tissues were homogenized by means of Ultra Turrax T25 homogenization and used for measuring malondialdehyde (MDA) levels with the thiobarbituric acid reactive substances (TBARS) method [29]. Plasma thiol groups were measured by Miao - Lin $\mathrm{Hu}$ calorimetric method using 2, 2 di-Nitro benzoic acid. Thiol groups by reducing this reagent produce a color complex that absorbs at $412 \mathrm{~nm}$ [30]. The FRAP assay was used to evaluate total antioxidant power in the liver homogenates of the four different groups. Antioxidant power in the samples reduced ferric to ferrous iron at low $\mathrm{pH}$ levels and led to the formation of a colored ferrous-tripyridyltriazine complex. The intensity of the colored complex was monitored at $593 \mathrm{~nm}$ [31].

\section{Pro-oxidant/antioxidant balance (PAB) assay}

To measure the Pro-Oxidant/Antioxidant Balance (PAB), the standard solution was prepared by mixing different ratios of $\mathrm{H}_{2} \mathrm{O}_{2}$ with uric acid. The TMB cation was prepared by mixing the TMB solution with 
chloramine $\mathrm{T}$. The working solution was also obtained by adding peroxidase enzyme to the TMB cation. Working solution was added to sample, standard or blank and absorbance was measured in an ELISA reader at $450 \mathrm{~nm}$ with a reference wavelength of 620 or $570 \mathrm{~nm}$ [32].

\section{Statistical analysis}

Data are expressed as means \pm SD. Using SPSS version 18software; the data were computed by one-way ANOVA procedure and Turkey's test. $P<0.05$ was considered statistically significant.

\section{Results}

Characterization of phytochemically synthesized gold NPs The jujube extracts have hydroxyl functional groups that can act as effective reducing agent for the reduction of $\mathrm{Au}+$ ions to form AuNPs. Figure 1 displays the UV-Vis spectra of the AUNPS from the reaction of different amount of extract $(1,2,4$ and $10 \mathrm{~mL})$ with $1 \mathrm{mM}$ $\mathrm{HAuCl} 4(20 \mathrm{~mL})$ after $2 \mathrm{~h}$. Due to the surface plasmon absorption of AuNPs, the maximum absorbance was at around $540 \mathrm{~nm}$. A sharp absorption peak at $542 \mathrm{~nm}$ was shown when used $4 \mathrm{~mL}$ of extract. The increment of intensity of absorption peak could be because of increasing number of the synthesized AuNPs. Therefore, $4 \mathrm{~mL}$ of extract was selected as the optimized amount of extract.

The conversion of $\mathrm{Au}+$ ions to $\mathrm{Au}$ nanoparticles was monitored by color change from pale yellow to dark purple which was shown in Fig. 2.

Although, after $10 \mathrm{~min}$ of addition of jujube extract to $\mathrm{HAuCl} 4.3 \mathrm{H} 2 \mathrm{O}$ solution, the dark purple color was appeared, but according to UV-Vis spectra, the absorbance peak intensity at $542 \mathrm{~nm}$ was increased and the reaction proceed with over time up to $2 \mathrm{~h}$. Also, no other new peak was seen in this interval (Fig. 3).

\section{TEM analysis of AuNPs}

The morphology and size of the synthesized AuNPs were investigated through high resolution transmission electron microscopy (HR-TEM). HR-TEM analysis was clearly revealed that low amount (1 and $2 \mathrm{~mL}$ ) and large amount $(10 \mathrm{~mL})$ of jujube extract lead to the formation of gold nanostructures with different shapes and sizes (Fig. 4). While, the completely spherical nanoparticles with almost uniform size were produced in the presence of $4 \mathrm{~mL}$ of extract. The particle size distribution of AuNPs found to be at the range of 7-27 $\mathrm{nm}$.

\section{X-ray diffraction pattern for AuNPs}

X-ray diffraction pattern of the AUNPS was exhibited in Fig. 5. As it could be seen, the obtained peaks were relatively broadened. The expanding of XRD peaks could be affected by physical parameters such as particle size [33]. Here, peak broadening of synthesized AuNPs could be related to small size of synthesized particles. The average particles diameter of $\mathrm{Au}$ nanoparticles was calculated using Debye Scherer's equation and found to be $18 \mathrm{~nm}$.

\section{Effect of AuNPs on biochemical parameters}

Effect of gold nanoparticles on the levels of body weight was studied by in vivo animal model. There was a reduction in body weight after induction of diabetes by streptozotocin. Treatment with AuNPs at the dose of $1 \mathrm{mg} /$

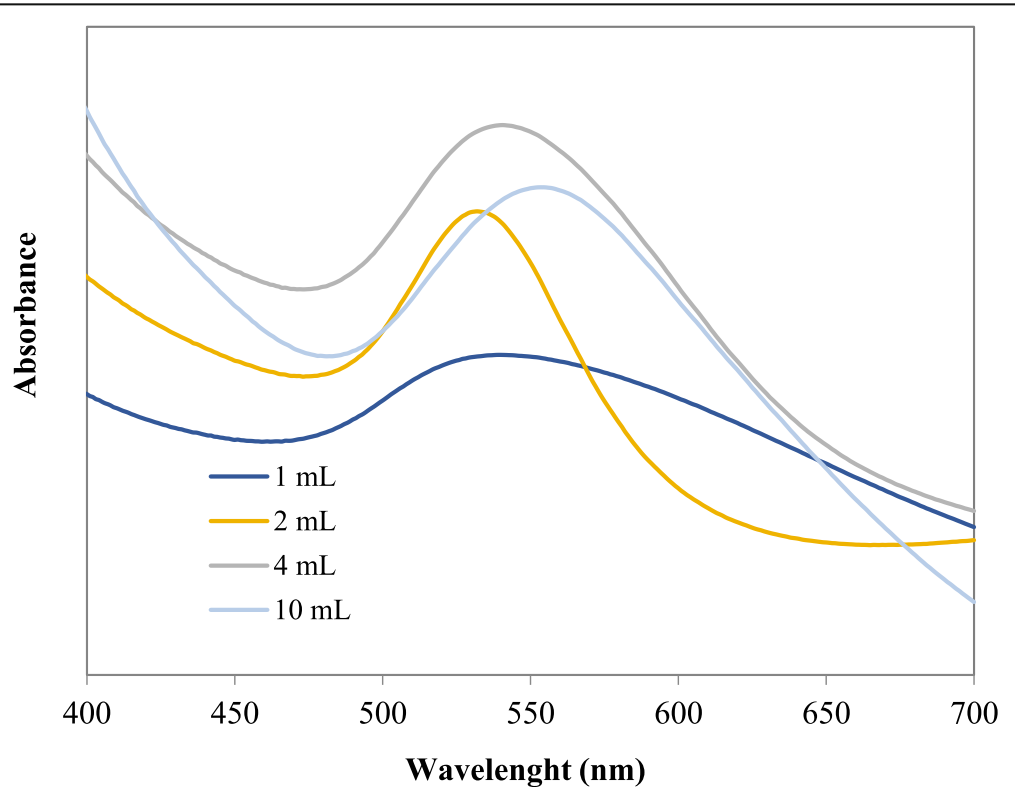

Fig. 1 UV-Vis spectra of the synthesized AuNPs using different amount of jujube extract after $2 \mathrm{~h}$ 


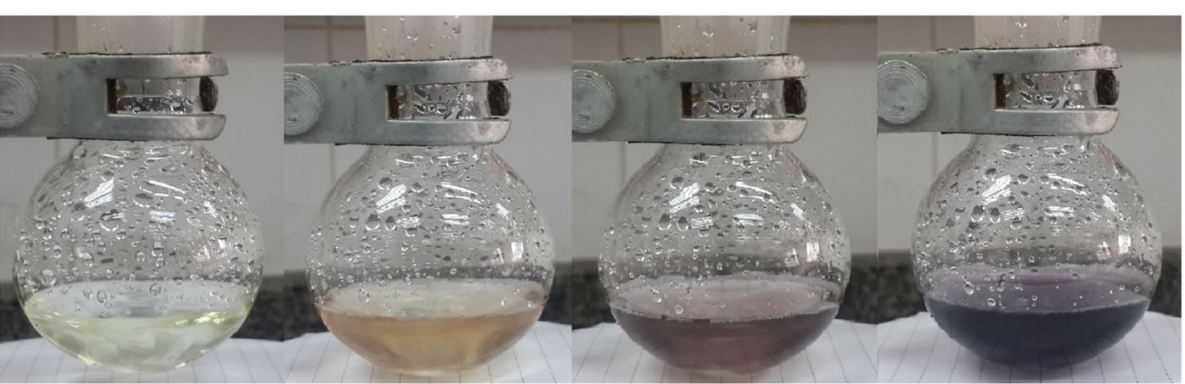

Fig. 2 Color change of solutions in AuNPs formation

kg b.w significantly increased body weight $(220 \pm 17.7 \mathrm{~g})$ when compared with the diabetic control rats (192 \pm $11.5 \mathrm{~g}$ ) (Table 1). The changes in the serum glucose concentration of normal and diabetic rats are presented in Table 1. The serum glucose concentration was significantly higher in diabetic rats as compared with normoglycemic rats. Treatment with jujube gold nanoparticles at the dose of $1 \mathrm{mg} / \mathrm{kg}$ b.w significantly decreased the serum glucose concentration to near that recorded in the normal rats $(p<0.05)$. As shown in Table 1 the mean values of insulin level and HOMA-IR in diabetic control group were $2.06 \pm 0.05 \mathrm{ng} / \mathrm{ml}$ and $84.80 \pm 0.86$ respectively. Treatment with jujube gold nanoparticles at the dose of $1 \mathrm{mg} / \mathrm{kg}$ b.w significantly increased HOMAIR $(p<0.001)$ and significantly increased for serum insulin level $(p<0.001)$. The level of vitamin $\mathrm{d}$ was significantly less in diabetic rats $(9.2 \pm 0.86 \mathrm{ng} / \mathrm{ml})$ as compared with normoglycemic rats $(19 \pm 0.70 \mathrm{ng} / \mathrm{ml})$. treatment with jujube gold nanoparticles at the dose of $1 \mathrm{mg} / \mathrm{kg}$ b.w significantly increased the serum vitamin D concentration to near that recorded in the normoglycemic rats $(p<0.001)$ (see Table 1). In diabetic rats the mean values of ALT, AST, and serum creatinine level and serum urea were $493 \pm 31.8 \mathrm{u} / \mathrm{l}, 520 \pm 27.05 \mathrm{u} / \mathrm{l}$, $0.84 \pm 0.05 \mathrm{mg} / \mathrm{dl}, 99 \pm 3.91 \mathrm{mg} / \mathrm{dl}$ respectively. While in group IV, these values were $90 \pm 9.34 \mathrm{u} / \mathrm{l}, 113 \pm 4.34 \mathrm{u} / \mathrm{l}$, $0.66 \pm 0.04 \mathrm{mg} / \mathrm{dl}, 70 \pm 9.36 \mathrm{mg} / \mathrm{dl}$ respectively. After the comparison between diabetic group and diabetic treated with jujube gold nanoparticles at the dose of $1 \mathrm{mg} / \mathrm{kg}$ b.w it was noticed that the mean values of ALT, AST, and serum urea were decreased significantly $(p<0.05)$. Treatment with gold nanoparticles in diabetic rats decreased serum creatinine level, but this decrease was not statistically significant $(P>0.05)$ (Table 2$)$. Table 3 show

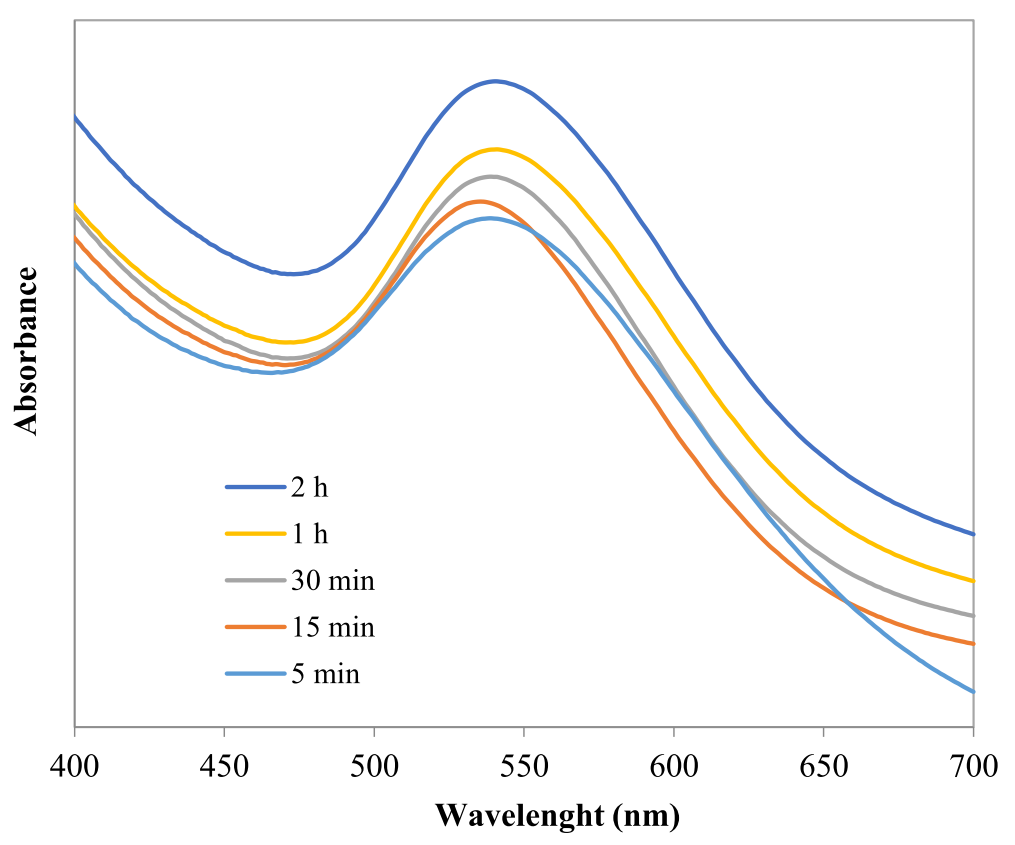

Fig. $3 \mathrm{UV}$-Vis spectra of AuNPs during reaction $25 \mathrm{~mL}$ of $\mathrm{HAuCl}_{4} .3 \mathrm{H}_{2} \mathrm{O}(1 \mathrm{mM})$ with $4 \mathrm{~mL}$ of Jujube extract after $5,15,30 \mathrm{~min}, 1$ and $2 \mathrm{~h}$ 


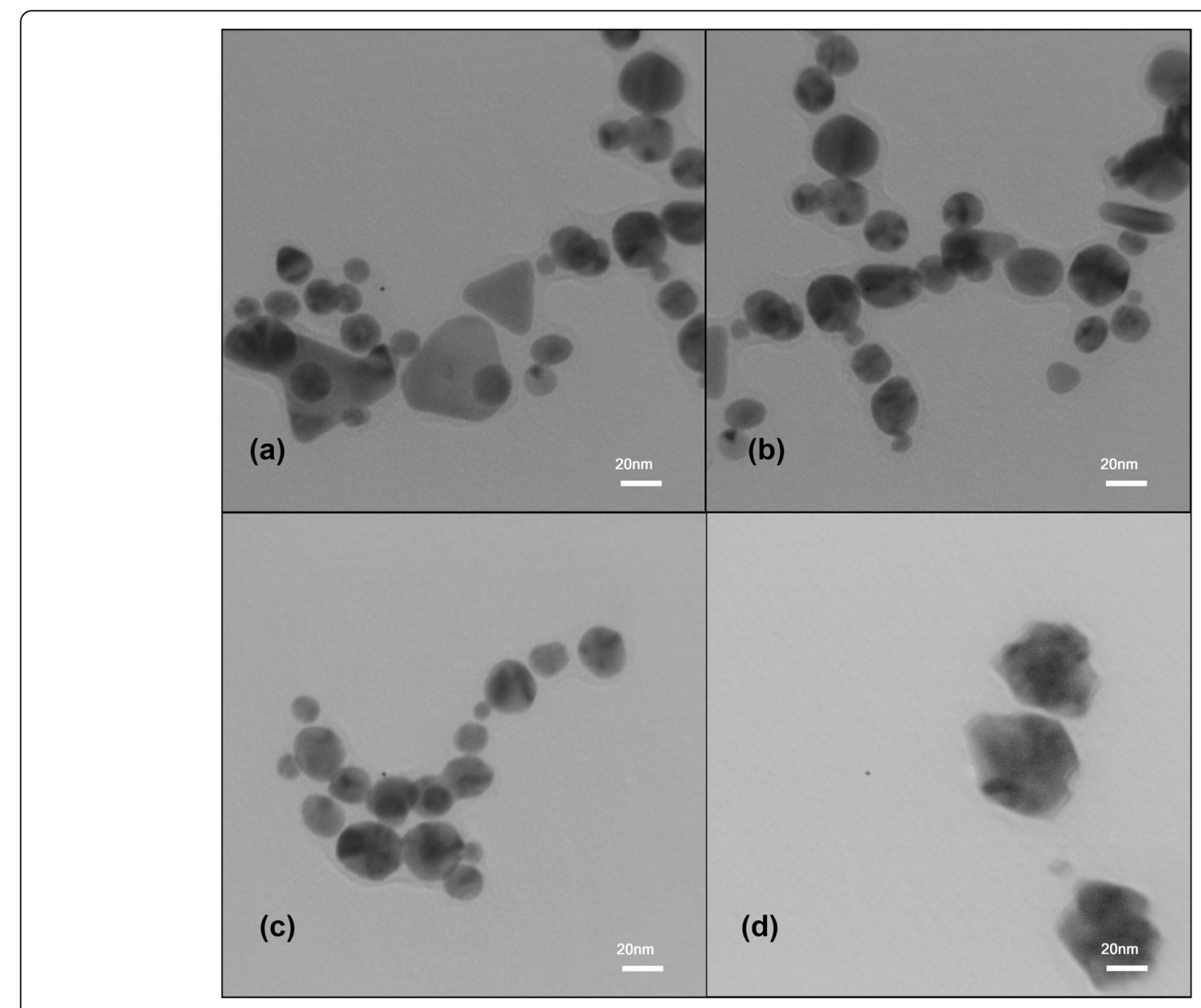

Fig. 4 TEM images of the synthesized AuNPs using different amounts of jujube extract [(a)1, (b)2, (c) 4 and (d) $10 \mathrm{~mL}]$

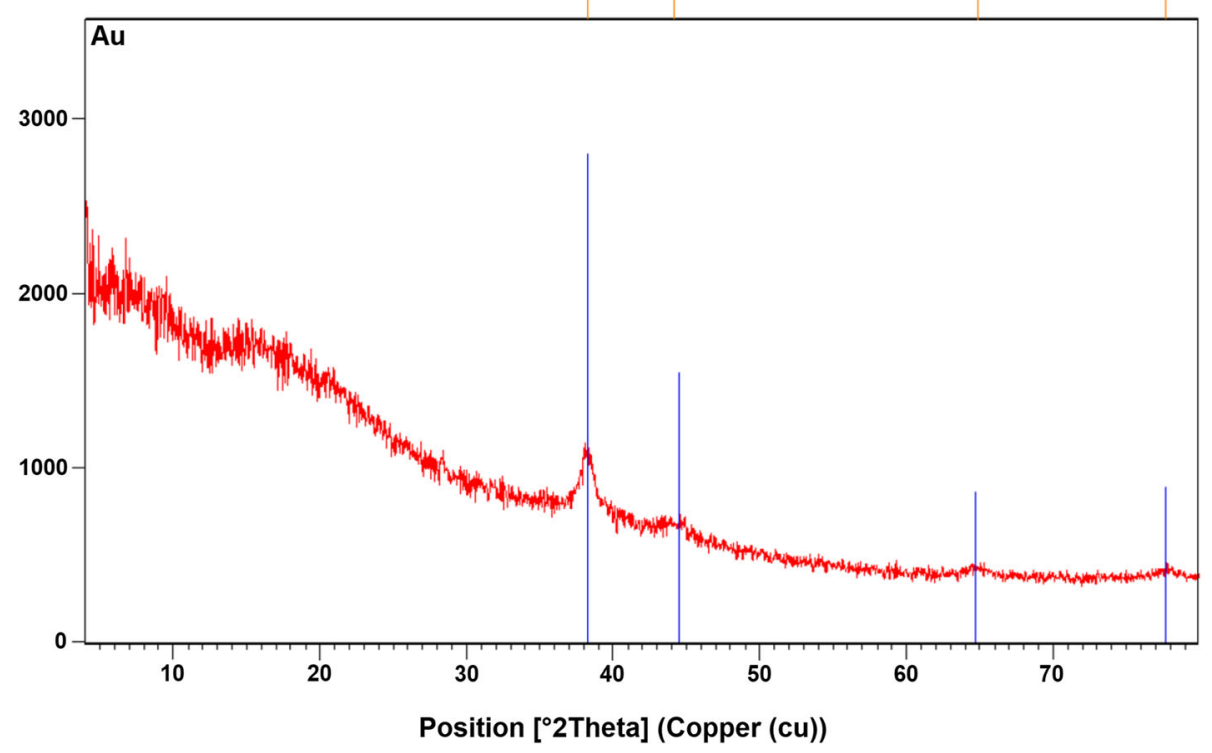

Fig. 5 XRD pattern of the synthesized AuNPs using jujube extract 
Table 1 Effect of AuNPs on biochemical parameters of experimental groups

\begin{tabular}{|c|c|c|c|c|c|c|c|}
\hline \multirow{2}{*}{$\begin{array}{l}\text { Experimental } \\
\text { groups }\end{array}$} & \multicolumn{2}{|c|}{ Body weight (gr) } & \multicolumn{2}{|c|}{ Fasting Blood Glucose (FBG) (mg/dL) } & \multirow{2}{*}{$\begin{array}{l}\text { Insulin } \\
\text { (ng/ml) }\end{array}$} & \multirow[t]{2}{*}{ HOMA-IR } & \multirow{2}{*}{$\begin{array}{l}\text { Vitamin D } \\
(\mathrm{ng} / \mathrm{ml})\end{array}$} \\
\hline & Initial & Final & Initial & Final & & & \\
\hline Groupl & $219 \pm 1.37$ & $278.4 \pm 4.67$ & $92.59 \pm 4.88$ & $102.8 \pm 8.88$ & $2.63 \pm 0.17$ & $18.00 \pm 0.70$ & $19.4 \pm 0.7$ \\
\hline \multirow[t]{2}{*}{ Groupll } & $219 \pm 1.31$ & $192.2 \pm 1.15$ & $476.21 \pm 12.36$ & $692 \pm 16.98$ & $2.06 \pm 0.05$ & $84.80 \pm 0.86$ & $9.2 \pm 0.86$ \\
\hline & $0.977^{\mathrm{a}}$ & $0.0001^{a}$ & $0.0001^{a}$ & $0.0001^{a}$ & $0.004^{\mathrm{a}}$ & $0.0001^{a}$ & $0.0001^{a}$ \\
\hline \multirow[t]{3}{*}{ GroupllI } & $220 \pm 1.63$ & $204 \pm 3.14$ & $470.62 \pm 7.62$ & $587 \pm 18.16$ & $2.13 \pm 0.05$ & $74.20 \pm 1.15$ & $11.12 \pm 0.7$ \\
\hline & $0.895^{\mathrm{a}}$ & $0.0001^{\mathrm{a}}$ & $0.0001^{a}$ & $0.0001^{\mathrm{a}}$ & $0.01^{\mathrm{a}}$ & $0.0001^{\mathrm{a}}$ & $0.0001^{\mathrm{a}}$ \\
\hline & $0.990^{\mathrm{b}}$ & $0.049^{\mathrm{b}}$ & $0.81^{b}$ & $0.121^{\mathrm{b}}$ & $0.96^{\mathrm{b}}$ & $0.0001^{b}$ & $0.46^{\mathrm{b}}$ \\
\hline \multirow[t]{4}{*}{ GrouplV } & $221 \pm 1.28$ & $220.2 \pm 1.77$ & $483.06 \pm 9.82$ & $281 \pm 14.59$ & $2.49 \pm 0.11$ & $40.60 \pm 1.07$ & $15.8 \pm 1.06$ \\
\hline & $0.692^{\mathrm{a}}$ & $0.0001^{\mathrm{a}}$ & $0.0001^{\mathrm{a}}$ & $0.121^{a}$ & $0.74^{\mathrm{a}}$ & $0.0001^{a}$ & $0.074^{\mathrm{a}}$ \\
\hline & $0.895^{b}$ & $0.0001^{b}$ & $0.88^{b}$ & $0.0001^{b}$ & $0.03^{b}$ & $0.0001^{b}$ & $0.0001^{b}$ \\
\hline & $0.977^{c}$ & $0.009^{c}$ & $0.67^{c}$ & $0.0001^{c}$ & $0.07^{c}$ & $0.0001^{c}$ & $0.005^{c}$ \\
\hline
\end{tabular}

Each value represents the mean \pm standard error of the mean $(n=5)$. The values were found to be statistically significant at $P<0.05$

a In comparison with group (I)

${ }^{b}$ In comparison with group (II)

c Comparison of Group III with Group IV

the effect of AuNPs on serum cholesterol, triglycerides, AIP, HDL-C and LDL-C levels. In diabetic rats, cholesterol, triglycerides, AIP, LDL-C levels were increased and HDL-C level was decreased compared to normal rats. Treatment with AuNPs $1 \mathrm{mg} / \mathrm{kg}$ b.w showed significant reduction in cholesterol, triglycerides and AIP $(p<$ 0. 001) compared with diabetic group but the level of HDL-C and LDL-C were not significant changed $(p>$ $0.05)$ as compared with diabetic group.

\section{Effect of gold NPs intake on oxidant/antioxidant status in diabetic rats}

As shown in Figs. 6 and 7, the diabetic rats significantly exhibited increased MDA levels $(2.39 \pm 0.11)$ and decreased total antioxidant $(227.6 \pm 18.64)$ compared to control rats respectively $(p<0.05)$. Treatment with jujube gold nanoparticles at the dose of $1 \mathrm{mg} / \mathrm{kg}$ b.w significantly decreased the liver MDA $(1.81 \pm 0.07)$ and also increased the total antioxidant $(231.80 \pm 17.64)$ in liver compared to the diabetic group $(p<0.05)$. Moreover, the mean concentration of thiol groups in the diabetic group $(265 \pm 11.78)$ significantly decreased compared to control groups $(P=0.001)$. Treatment with jujube gold nanoparticles at the dose of $1 \mathrm{mg} / \mathrm{kg}$ b.w in diabetic rats had increased the concentration of thiol groups $(301 \pm 7.30)$ compared to the diabetic group, but this increase was not statistically significant $(P=0.18)$ (see Fig. 8). The mean of PAB levels in diabetic group was significantly higher than the healthy group (Fig. 9). In diabetic rats administration of AuNPs at the dose of $1 \mathrm{mg} / \mathrm{kg}$ significantly reduced the $\mathrm{PAB}$ levels $(p<0.001)$ compared to diabetic rats.

Table 2 The effect of AuNPs on the activity of hepatic and kidney enzymes in different experimental groups

\begin{tabular}{|c|c|c|c|c|}
\hline Experimental groups & $\operatorname{ALT}(\mathrm{U} / \mathrm{L})$ & AST(U/L) & urea $(\mathrm{mg} / \mathrm{dl})$ & Creatinine (mg/dl) \\
\hline Groupl & $64 \pm 5.59$ & $136 \pm 16.81$ & $56 \pm 4.14$ & $0.58 \pm 0.03$ \\
\hline \multirow[t]{2}{*}{ Groupll } & $493 \pm 31.8$ & $520 \pm 27.05$ & $99 \pm 3.91$ & $0.84 \pm 0.05$ \\
\hline & $0.0001^{\mathrm{a}}$ & $0.0001^{a}$ & $0.001^{a}$ & $0.011^{a}$ \\
\hline \multirow[t]{3}{*}{ GroupllI } & $232 \pm 17.78$ & $306 \pm 24.05$ & $87 \pm 6.36$ & $0.76 \pm 0.06$ \\
\hline & $0.0001^{\mathrm{a}}$ & $0.0001^{\mathrm{a}}$ & $0.016^{\mathrm{a}}$ & $0.094^{\mathrm{a}}$ \\
\hline & $0.0001^{b}$ & $0.0001^{b}$ & $0.54^{\mathrm{b}}$ & $0.68^{b}$ \\
\hline \multirow[t]{4}{*}{ GrouplV } & $90 \pm 9.34$ & $113 \pm 4.34$ & $70 \pm 9.36$ & $0.66 \pm 0.04$ \\
\hline & $0.766^{\mathrm{a}}$ & $0.861^{\mathrm{a}}$ & $0.403^{\mathrm{a}}$ & $0.683^{\mathrm{a}}$ \\
\hline & $0.0001^{b}$ & $0.0001^{b}$ & $0.02^{b}$ & $0.09^{b}$ \\
\hline & $0.0001^{c}$ & $0.0001^{c}$ & $0.29^{c}$ & $0.517^{c}$ \\
\hline
\end{tabular}

\footnotetext{
Each value represents the mean \pm standard error of the mean $(n=5)$. The values were found to be statistically significant at $P<0.05$

a In comparison with group (I)

b In comparison with group (II)

c Comparison of GroupllI with GrouplV
} 
Table 3 Effect of AuNPs on lipid profile of experimental groups

\begin{tabular}{|c|c|c|c|c|c|}
\hline Experimental Groups & Triglycerides (mg/dl) & Total cholesterol (mg/dl) & HDL-C (mg/dl) & LDL-C (mg/dl) & AIP \\
\hline Group I & $45 \pm 6.42$ & $104 \pm 3.33$ & $43 \pm 0.51$ & $56 \pm 2.00$ & $0.36 \pm 0.01$ \\
\hline \multirow[t]{2}{*}{ Groupll } & $94 \pm 7.23$ & $153 \pm 4.72$ & $33 \pm 1.6$ & $72 \pm 1.80$ & $0.66 \pm 0.03$ \\
\hline & $0.0001^{a}$ & $0.0001^{\mathrm{a}}$ & $0.002^{\mathrm{a}}$ & $0.0001^{\mathrm{a}}$ & $0.0001^{\mathrm{a}}$ \\
\hline \multirow[t]{3}{*}{ Group III } & $72 \pm 3.91$ & $132 \pm .04$ & $31 \pm 2.1$ & $71 \pm 1.43$ & $0.62 \pm 0.07$ \\
\hline & $0.037^{\mathrm{a}}$ & $0.0001^{a}$ & $0.0001^{\mathrm{a}}$ & $0.0001^{\mathrm{a}}$ & $0.0001^{\mathrm{a}}$ \\
\hline & $0.108^{b}$ & $0.004^{b}$ & $0.85^{b}$ & $0.97^{b}$ & $0.025^{b}$ \\
\hline \multirow[t]{4}{*}{ Group IV } & $54 \pm 7.28$ & $113 \pm 2.55$ & $36 \pm 1.64$ & $69 \pm 1.18$ & $0.48 \pm 0.02$ \\
\hline & $0.739^{a}$ & $0.253^{\mathrm{a}}$ & $0.021^{\mathrm{a}}$ & $0.0001^{\mathrm{a}}$ & $0.0001^{\mathrm{a}}$ \\
\hline & $0.002^{b}$ & $0.0001^{b}$ & $0.71^{b}$ & $0.43^{b}$ & $0.0001^{b}$ \\
\hline & $0.229^{c}$ & $0.008^{c}$ & $0.278^{c}$ & $0.681^{c}$ & $0.0001^{c}$ \\
\hline
\end{tabular}

Each value represents the mean \pm standard error of the mean $(n=5)$. The values were found to be statistically significant at $P<0.05$

a In comparison with group (I)

${ }^{b}$ In comparison with group (II)

${ }^{c}$ Comparison of Grouplll with GrouplV

\section{Discussion}

Effect of AuNPs on blood glucose, insulin, HOMA-IR, body weight and vitamin $\mathrm{D}$ levels in diabetic rats

According to the data obtained in this study, treatment of diabetic rats with AuNPs ( $1 \mathrm{mg} / \mathrm{kg} . \mathrm{b.w})$ for 21 days, improved glucose metabolism. These results are consistent with previous studies presented by Husam et al. that proved anti-diabetic potential of AuNPs [9]. The proposed mechanism for this action of AuNPs (1 mg/ kg.b.w) was by improving the pancreatic beta cells. Our findings are consistent with those of A. Nirmala, who reported that treatment with AuNPs significantly reduces blood glucose concentration and increases insulin secretion [34]. The Homeostasis Model Assessment of IR (HOMA-IR) is the most important indicator for assessing insulin resistance. In this study, the comparison between different groups showed that the mean level of HOMA-IR in the diabetic group was highest and AuNPs reduced the insulin resistance. Some animal studies have shown that levels of vitamin $\mathrm{D}$ in diabetic rats are significantly reduced [35]. In this study, vitamin D level in diabetic rats was lower than healthy ones. Studies suggest that insulin deficiency in diabetic rats disrupts $\alpha-1$ hydroxylation of 25-OH-D and reduces vitamin D levels $[36,37]$. It seems the nanoparticles return the level of vitamin $\mathrm{D}$ to the normal level through induction of insulin secretion. Diabetic rats showed a significant reduction in body weight and fluid intake. The presence of hyperglycemia causes weight loss in rats tested [38]. Our studies have shown that treatment of diabetic rats with AuNPs were able to improve their body weight due to improved insulin secretion and glycemic control. The possible mechanism for this gain in body weight is the effect of controlling muscle wasting [8, 35].

\section{Effect of AuNPs on hepatic and renal marker levels in serum}

ALT and AST enzymes are indicators for the proper functioning of the liver. Hyperglycemia causes irreversible damage to the hepatocytes. Administration of AuNPs ( $1 \mathrm{mg} / \mathrm{kg} . \mathrm{b} . \mathrm{w})$ for 21 days in diabetic rats significantly reduced the level of ALT, AST enzymes that

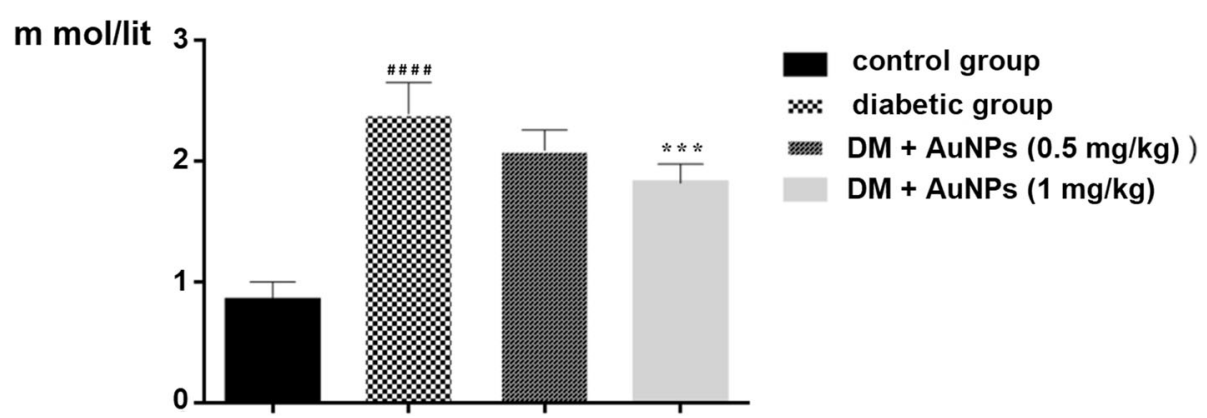

Fig. 6 Effect of AuNPs on malondialdehyde experimental groups of rats after 21 days treatment. Data are reported to mean \pm SD of 5 rats in each grou. ${ }^{*}, * * * * *$,and ${ }^{* * *}$ represent statistically significant differences from Diabetic group at $p<0.05,0.01,0.001$ and 0.0001, respectively \#, \#\#, \#\#\#, and \#\#\#\#represents statistically significant difference from control group at $p<0.05,0.01,0.001$ and 0.0001 , respectively 


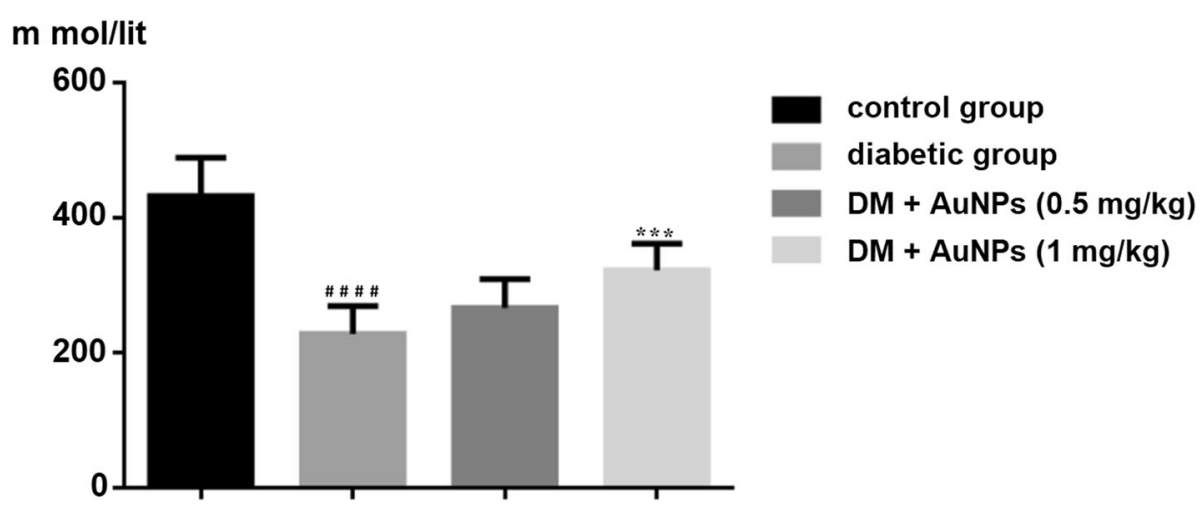

Fig. 7 Effect of AuNPs on FRAP experimental groups of rats after 21 days treatment. Data are reported to mean \pm SD of 5 rats in each group. * *****,and****represent statistically significant differences from Diabetic group at $p<0.05,0.01,0.001$ and 0.0001 , respectively. \#, \#\#, \#\#\#, and \#\#\#\#represents statistically significant difference from control group at $p<0.05,0.01,0.001$ and 0.0001 , respectively

confirmed protective effects of AuNPs on hepatocyte. Our results coincide with findings Patrick et al., who stated that treatment with AuNPs reduces the level of transaminases in STZ-diabetic rats [35]. Hyperglycemia increases the plasma levels of urea and creatinine, which indicates kidney damage during diabetes [39]. In the present study, the level of urea and creatinine in diabetic rats showed a significant increase compared to healthy rats. During the treatment with AuNPs, levels of creatinine reached normal that indicates the favorable role of AuNPs in preventing kidney damage.

\section{Effect of AuNPs on the lipid profiles}

Hyperglycemia increases the level of lipids in the body. By increasing the free fatty acids from the adipose tissue and secreting them to the bloodstream, the level of fat increases. Such an increase in fat content will increase cardiovascular and atherosclerotic disease. In diabetic rats there was a significant increase in cholesterol and triglyceride levels and decrease in HDL-C. Treatment with green AuNPs decreased triglyceride level close to normal which indicates the hypolipidemia effect of AuNPs. The atherogenic index of plasma (AIP) is a strong indicator of the risk of atherosclerosis and cardiovascular disease [40, 41]. AIP is calculated as log (TG/ HDL-C), and can be used as a monitoring indicator for CVD [42]. In diabetic rats, the amount of AIP increases due to decreased HDL-C and increased TG levels. Treatment with AuNPs reduced the amount of AIP by decreasing TG levels.

\section{Effect of gold NPs intake on oxidant/antioxidant status in diabetic rats}

In the normal state, there is a balance between prooxidant production and antioxidant defense. In diabetes, due to the increased production of free radicals, there is an imbalance between pro-oxidant mechanisms and antioxidant defense. The antioxidant activity of AuNPs was evaluated through Prooxidant-antioxidant balance (PAB) assay test. Among the antioxidants used to treat

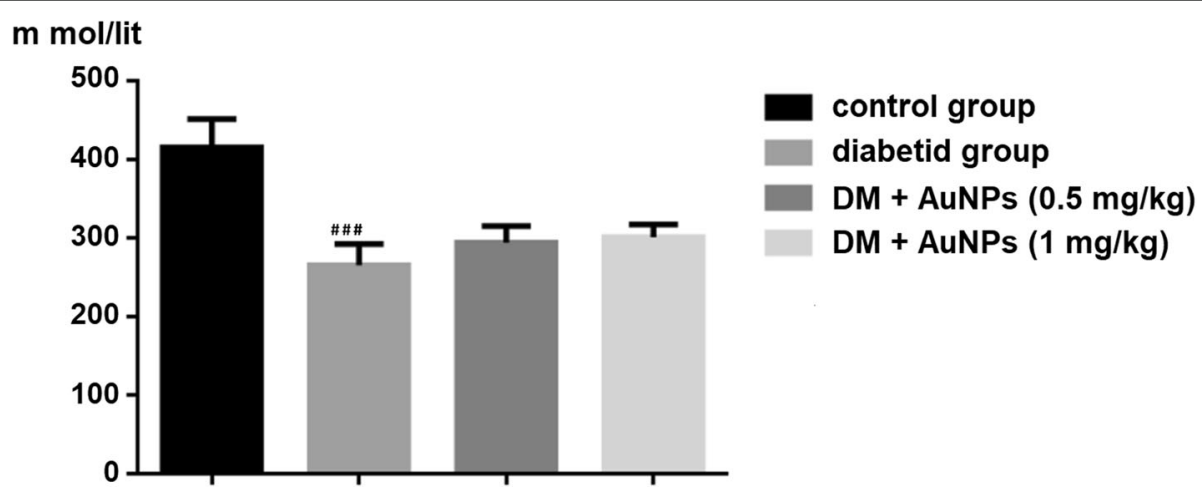

Fig. 8 Effect of AuNPs on Plasma thiol groups experimental groups of rats after 21 days treatment. Data are reported to mean \pm SD of 5 rats in each group. ${ }^{*}, * * * * *$,and ${ }^{* * * *}$ represent statistically significant differences from Diabetic group at $p<0.05,0.01,0.001$ and 0.0001 , respectively. \#, \#\#, \#\#\#, and \#\#\#\#represents statistically significant difference from control group at $p<0.05,0.01,0.001$ and 0.0001 , respectively 


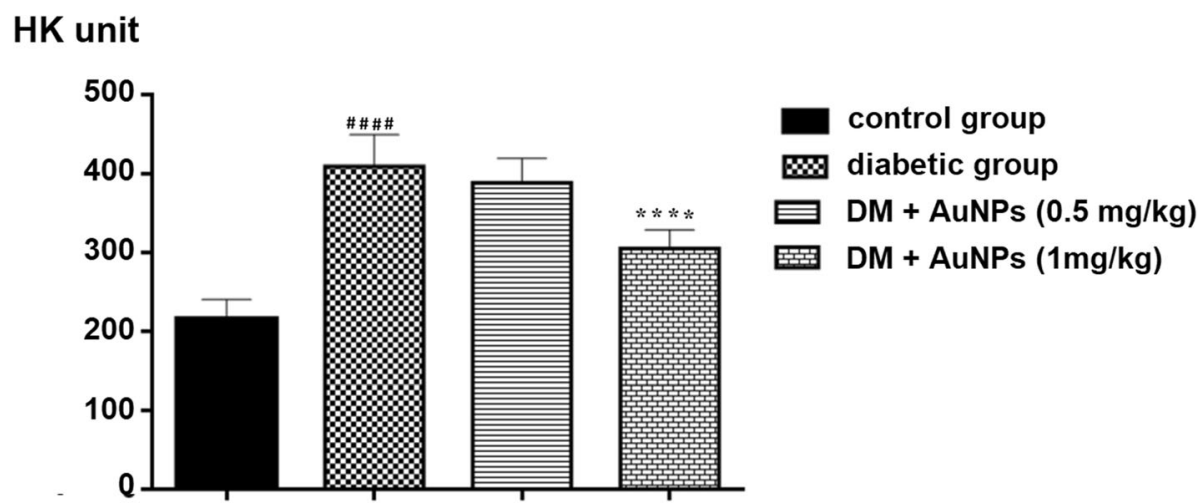

Fig. 9 Effect of AuNPs on PAB level experimental groups of rats after 21 days treatment. Data are reported to mean \pm SD of 5 rats in each group. *, *****,and***represent statistically significant differences from Diabetic group at $p<0.05,0.01,0.001$ and 0.0001 , respectively. \#, \#\#, \#\#\#, and \#\#\#\#represents statistically significant difference from control group at $p<0.05,0.01,0.001$ and 0.0001 , respectively

oxidative diseases like diabetes, nanoparticles have important role. The antioxidant properties of nanoparticles have been reported in a variety of ways, such as DPPH test. In this study, the PAB method was used to determine the antioxidant properties of synthesized nanoparticles. One of the benefits of this approach is quick, easy, and affordable. This study showed the antioxidant property of green nanoparticles that can reduce tissue oxidants. The results of the present study showed that the induction of diabetes in rats increased MDA level, decreased TAC level in their liver. Daily administration of jujube gold nanoparticles to diabetic rats decreased MDA levels but increased TAC. Therefore, jujube gold nanoparticles gradually can reduce diabetes complications by reducing lipid peroxidation and oxidative stressinduced diabetes. Our results coincide with findings AlAzzawie HF who stated that treatment with AuNPs reduces the level of MDA and increased TAC level in STZ-diabetic rats [8].

\section{Conclusion}

The results of this study showed that jujube fruit extract has a high ability to revive gold ions and convert them to gold metal atoms. Production of nanoparticles in this way is affordable and takes very little time. The antioxidant and anti-diabetic activity of nanoparticles synthesized using jujube fruit extract was proven in this study.

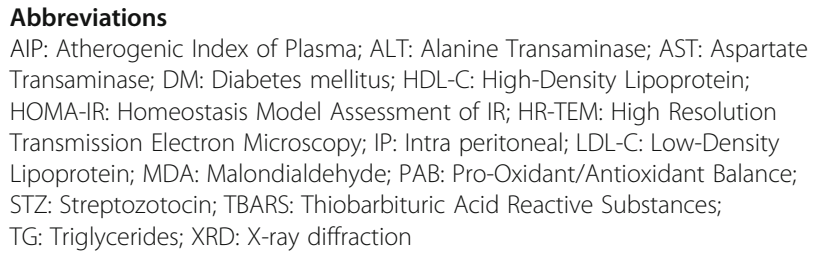

AIP: Atherogenic Index of Plasma; ALT: Alanine Transaminase; AST: Aspartate Transaminase; DM: Diabetes mellitus; HDL-C: High-Density Lipoprotein; HOMA-IR: Homeostasis Model Assessment of IR; HR-TEM: High Resolution Transmission Electron Microscopy; IP: Intra peritoneal; LDL-C: Low-Density Lipoprotein; MDA: Malondialdehyde; PAB: Pro-Oxidant/Antioxidant Balance; STZ: Streptozotocin; TBARS: Thiobarbituric Acid Reactive Substances; TG: Triglycerides; XRD: X-ray diffraction

\section{Acknowledgements}

The authors of this article would like to express their appreciation to the Vice-Chancellor for Research and Technology of Birjand University of Medical
Sciences for funding this study and all those who helped us in performing this study.

\section{Authors' contributions}

$\mathrm{RJ}, \mathrm{MH}^{\mathrm{b}}$ and $\mathrm{MH}^{\mathrm{d}}$ make substantial contributions to conception and design, and acquisition of data, and analysis and interpretation of data. $\mathrm{RJ}, \mathrm{MH}^{\mathrm{C}}$ and $\mathrm{MH}^{\mathrm{d}}$ participate in drafting the article or revising it critically for important intellectual content. All authors give final approval of the version to be submitted and any revised version.

Funding

Not applicable.

Availability of data and materials

All the data is contained in the manuscript.

\section{Ethics approval}

The Research Ethics Committee of Birjand University of Medical Sciences approved all ethical considerations of working on laboratory animals (Ethics Code: IR.Bums.REC.1396.329).

\section{Consent for publication}

Not applicable.

\section{Competing interests}

The authors declare that they have no competing interest.

\section{Author details}

'Student Research Committee, Birjand University of Medical Sciences, Birjand 9717853577, Iran. ${ }^{2}$ Department of Chemical Engineering, Birjand University of Technology, Birjand, Iran. ${ }^{3}$ Cellular and Molecular Research Center,

Department of Anatomical Sciences, Birjand University of Medical Sciences, Birjand 9717853577, Iran. ${ }^{4}$ Biochemistry Department, Faculty of Medicine, Zanjan University of Medical sciences, Zanjan 4513956111, Iran. ${ }^{5}$ Biochemistry Department, Faculty of Medicine, Birjand University of Medical Sciences, Birjand 9717853577, Iran.

Received: 19 April 2020 Accepted: 3 November 2020

Published online: 11 November 2020

\section{References}

1. Dong H, Wang N, Zhao L. Hindawi Publishing Corporation Evidence-Based Complementary and Alternative Medicine. 2012:12. Article ID 591654. https://doi.org/10.1155/2012/591654

2. Yin J, Xing $\mathrm{H}, \mathrm{Ye} \mathrm{J}$. Efficacy of berberine in patients with type 2 diabetes mellitus. Metabolism. 2008:57(5):712-7.

3. Marso SP, Bain SC, Consoli A, Eliaschewitz FG, Jódar E, Leiter LA, et al. Semaglutide and cardiovascular outcomes in patients with type 2 diabetes. New England J Med. 2016;375(19):1834-44. 
4. Aronson D. Hyperglycemia and pathobiology of diabetic complications. Adv Cardiol. 2008;45:1-16.

5. Borchers AT, Uibo R, Gershwin ME. The geoepidemiology of type 1 diabetes. Autoimmun Rev. 2010;9(5):A355-65.

6. Wells IC. Evidence that the etiology of the syndrome containing type 2 diabetes mellitus results from abnormal magnesium metabolism. Can J Physiol Pharmacol. 2008;86:16-24.

7. Prashant KJ, Kyeong SL, El-Sayed IH, El-Sayed MA. Calculated absorption and scattering properties of AUNPS of different size, shape, and composition: applications in biological imaging and biomedicine. J Phys Chem B. 2006; 110:7238-48.

8. Al-Azzawie HF, Yaaqoob LA. Hypoglycemic and antioxidant effects of gold nanoparticals in alloxan-induced diabetes rats. Int J Res Biotechnol Biochem. 2016;6(1):12-20.

9. Edrees HM, Elbehiry A, Elmosaad YM. Hypoglycemic and anti-inflammatory effect of gold nanoparticles in streptozotocin-induced type 1 diabetes in experimental rats. Nanotechnology. 2017:3:4

10. Giljohann DA, Seferos DS, Daniel WL, Massich MD, Patel PC, Mirkin CA. AUNPS for biology and medicine. Angew Chem Int Ed Engl. 2010;49(19): 3280-94.

11. Mekheimer KS, Hasona WM, Abo-Elkhair RE, Zaher AZ. Peristaltic blood flow with AUNPS as a third grade nanofluid in catheter: application of cancer therapy. Phys Lett A. 2018;382:85-93.

12. Vial S, Reis RL, MiguelOliveira J. Recent advances using AUNPS as a promising multimodal tool for tissue engineering and regenerative medicine. Curr Opin Solid State Mater Sci. 2017;21:92-112.

13. Ayuk Eugene L, Ugwu Mariagoretti O, Aronimo SB. A review on synthetic methods of nanostructured materials. Chem Res J. 2017;2(5):97-123.

14. Yeh YC, Creran B, Rotello VM. AUNPS: preparation, properties, and applications in bionanotechnology. Nanoscale. 2012;4:1871.

15. Philip D. Green synthesis of gold and silver nanoparticles using Hibiscus rosa sinensis. Phys E Low Dimensional Syst Nanostructures. 2010;24:1417-24.

16. Raya Zach PE, Hazan S, Kolusheva S, Porat Z, Zeiri Y. Green synthesis of AUNPS using plant extracts as reducing agents. Int J Nanomedicine. 2014;9: 4007-21.

17. Shabestarian H, Homayouni-Tabrizi M, Soltani M, Namvar F, Azizi S, Mohamad R, et al. Green synthesis of AUNPS using sumac aqueous extract and their antioxidant activity. Materials Res. 2017:20(1):264-70.

18. Pérez BA, García-Hernández L, Ramírez Ortega PA, Arenas ID. Green synthesis of AUNPS (AuNPs) using the extract of sedum Praealtum. ECS Transact. 2018;84(1):321-30.

19. Zheng H, Lu HF, Zheng YP, Lou HQ, Chen CQ. Automatic sorting of Chinese jujube (Zizyphus jujuba mill.cv.'hongxing') using chlorophyll fluorescence and support vector machine. J Food Eng. 2010;101:402-8.

20. Yu L, Jiang BP, Luo D, Shen XC, Guo S, Duana JA, et al. Bioactive components in the fruits of Ziziphus ujube mill. Against the inflammatory irritant action of Euphorbia plants. Phytomed. 2012;19:239-44.

21. Pahuja M, Mehla J, Reeta KH, Joshi S, Kumar GY. Hydroalcoholic extract of Zizyphus ujube ameliorates seizures, oxidative stress, and cognitive impairment in experimental models of epilepsy in rats. Epilepsy Behav. 2011;21:356-63.

22. Hemmati M, Asghari S, Zohoori E. Effects of alcoholic and aqueous extract of barberry, Jujube and saffron petals on serum level of Adiponectin and lipid profile in diabetic rats. Iran J Endocrinol Metab. 2015;16(5):329-37.

23. Kirubha $R$, Alagumuthu G. Production of biogenic AUNPS using Ziziphus Jujuba fruit extract. World J Pharm Sci. 2014;2(11):1469-74.

24. Kirubha R, Alagumuthu G. Production of biogenic silver nanoparticles using Ziziphus Jujuba fruit extract. Intern J Pharmaceutic Res Bio-Science. 2014; 3(5):287-97.

25. Yuan CG, Huo C, Gui B, Liu JF, Chen YS. Facile phyto-mediated synthesis of silver nanoparticles using Chinese winter jujube (Ziziphus jujuba Mill. Cv. Dongzao) extract and their antibacterial/catalytic properties. IET Nanobiotechnol. 2017;11(8):973-80.

26. Jafarizad A, Safaee K, Ekinci D. Green Synthesis of AUNPS Using Aqueous Extracts of Ziziphus jujuba and Gum arabic. J Clust Sci. 2017;28(5):2765-77.

27. Sreekanth TVM, Pandurangan M, Jung MJ, Lee YR, Eom IY. Eco-friendly decoration of graphene oxide with green synthesized silver nanoparticles: cytotoxic activity. Res Chem Intermediates. 2016;42(6):5665-76.

28. Nwagha UI, Ikekpeazu EJ, Ejezie FE, Neboh EE, Maduka IC. Atherogenic index of plasma as useful predictor of cardiovascular risk among postmenopausal women in Enugu, Nigeria. Afr Health Sci. 2010;10:248-52.
29. Yagi K. A simple fluorometric assay for lipoperoxide in blood plasma. Biochem Med. 1976;15(2):212-6.

30. Hu ML. Measurement of protein thiol groups and glutathione in plasma. Methods Enzymol. 1994;233:380-5. https://doi.org/10.1016/s00766879(94)33044-1.

31. Benzie IF, Strain J. The ferric reducing ability of plasma (FRAP) as a measure of "antioxidant power": the FRAP assay. Anal Biochem. 1996;239(1):70-6.

32. Alamdari DH, Aghasizadeh-Sharbaf M, Mohadjerani M, Ferns GA, Avan A. Prooxidant-antioxidant balance and antioxidant properties of Thuja orientalis L: a potential therapeutic approach for diabetes mellitus. Curr Mol Pharmacol. 2018;11(2):109-12.

33. Lipson $\mathrm{H}$, Steeple $\mathrm{H}$. Interpretation of X-ray powder diffraction patterns. London: Macmillan; 1970.

34. Daisy P, Saipriya K. Biochemical analysis of Cassia fistula aqueous extract and phytochemically synthesized gold nanoparticles as hypoglycemic treatment for diabetes mellitus. Int J Nanomedicine. 2012;7:1189.

35. Patrick EE, Item JA, Eyong UE, Goldwin EE. The anti-diabetic efficacy of combined extracts from two conventional plants; Azadirachta indica and Vernonia amygdalina (African Biiter leaf). Am J Biochem Biotechnol. 2008;4: 239-44.

36. Schneider LE, Schedl HP. Diabetes and intestinal calcium absorption in the rat. Am J Phys. 1972:223:1319-23.

37. Schneider LE, Wilson HD, Schedl HP. Effects of alloxan diabetes on duodenal calcium- binding protein in the rat. Am J Phys. 1974;227:832-8.

38. Shirwaikar A, Rajendran K, Barik R. Effect of aqueous bark extract of Garuga pinnata Roxb. In streptozotocin-nicotinamide induced type-II diabetes mellitus. J Ethnopharmacol. 2006;107:285-90.

39. Dhas TS, Kumar VG, Karthick V, Vasanth K, Singaravelu G, Govindaraju K Effect of biosynthesized gold nanoparticles by Sargassum swartzii in alloxan induced diabetic rats. Enzym Microb Technol. 2016:95:100-6.

40. Lopez AD, Mathers CD, Ezzati M, Jamison DT, Murray CJ. Global and regional burden of disease and risk factors, 2001: systematic analysis of population health data. Lancet. 2006:367:1747-57.

41. Dobiášová M. Atherogenic index of plasma [log (triglycerides/HDLcholesterol)]: theoretical and practical implications. Clin Chem. 2004;50(7): 1113-5.

42. Dobiasova M. AlP--atherogenic index of plasma as a significant predictor of cardiovascular risk: from research to practice. Vnitr Lek. 2006;52(1):64-71.

\section{Publisher's Note}

Springer Nature remains neutral with regard to jurisdictional claims in published maps and institutional affiliations.

\section{Submit your manuscript to a SpringerOpen ${ }^{\circ}$ journal and benefit from:}

- Convenient online submission

- Rigorous peer review

- Open access: articles freely available online

High visibility within the field

- Retaining the copyright to your article

Submit your next manuscript at $>$ springeropen.com 